\title{
Unique Cracking Observations in Superheater Tubes
}

\author{
Dustin A. Turnquist ${ }^{*}$ and George J. Theus ${ }^{* *}$ \\ * Engineering Systems Incorporated, 4775 Centennial Blvd., Suite 106, Colorado Springs, CO 80919 \\ ** Engineering Systems Incorporated, 3851 Exchange Ave., Aurora, IL 60504
}

Two vertical primary superheater tubes, from a fossil fuel fired power plant, were provided for metallurgical analysis. The boiler is a radiant heat, natural circulation reheat, bent tube, drum type boiler designed for pulverized coal firing. The approximate primary super-heater outlet pressure is $\sim 1900$ PSIG at $900^{\circ} \mathrm{F}$. The unit had been in service approximately $\sim 185,000$ hours when the tubes were removed.

A 4-inch length was cut from each tube. The tube lengths were then split longitudinally. The ID appearance of each piece was photo documented, FIG $1(\sim 2 \mathrm{X})$. The scale on the ID was relatively smooth and did not show signs of exfoliation. Scale is an indicator of the quality of the steam and the temperature at which the unit has been operated. One tube had the ID surface appearance similar to "alligator hide" or "elephant hide". A small piece was prepared for metallographic examination. The sample was polished down to $1-\mu \mathrm{m}$. The as-polished surface was examined for creep cavities. The sample was then etched in a $3 \%$ Nital solution. The microstructure consisted of ferrite and decomposed, spheroidized pearlite. The amount of decomposition was consistent with the operating conditions and time in service. There were no indications of creep damage.

Examination of the near ID features of one of the tubes showed areas of localized pitting attack, FIGS 2 and $3(\sim 190 X, \sim 120 X)$. The attack only occurred in one of the two tubes examined. It is unknown if the damage occurred recently, at start-up, prior to start-up, or had progressed over time.

The localized attack features suggest that the tube, with approximately $900^{\circ} \mathrm{F}$ steam inside, was periodically subjected to cooler aqueous or wet steam environments. Because of the pitting nature of the attack, aqueous corrosion might be suspected. However, the tube's orientation in the boiler was vertical and the attack is along the length of the tube and spans about a $30^{\circ}$ arc of its circumference (see FIG 1). Thus, it is difficult to envision how this tube would suffer aqueous corrosion damage while in service. It is noted that it is possible the observed damage occurred prior to erection of the boiler.

The attack morphology ("elephant hide" appearance and pitting) also suggests thermal fatigue usually observed on the ID of water carrying tubes. A possible explanation for this unusual type of attack in a super heater is that the tube was periodically subjected to cooler aqueous or wet steam environments and thus was exposed to cyclic stresses. This might occur near the super heater inlet or near the attemperators. A few super heater tubes at these locations have been examined by colleagues in the past where this rare type of attack was observed.

Additional metallographic examination of tube sections operating in this region of the super heater is recommended to assist in determining whether the observed attack is only in one tube (manufacturing anomaly) or is present in adjacent tubes (operating problems). During the same examinations, initiation of creep damage can also be assessed. 


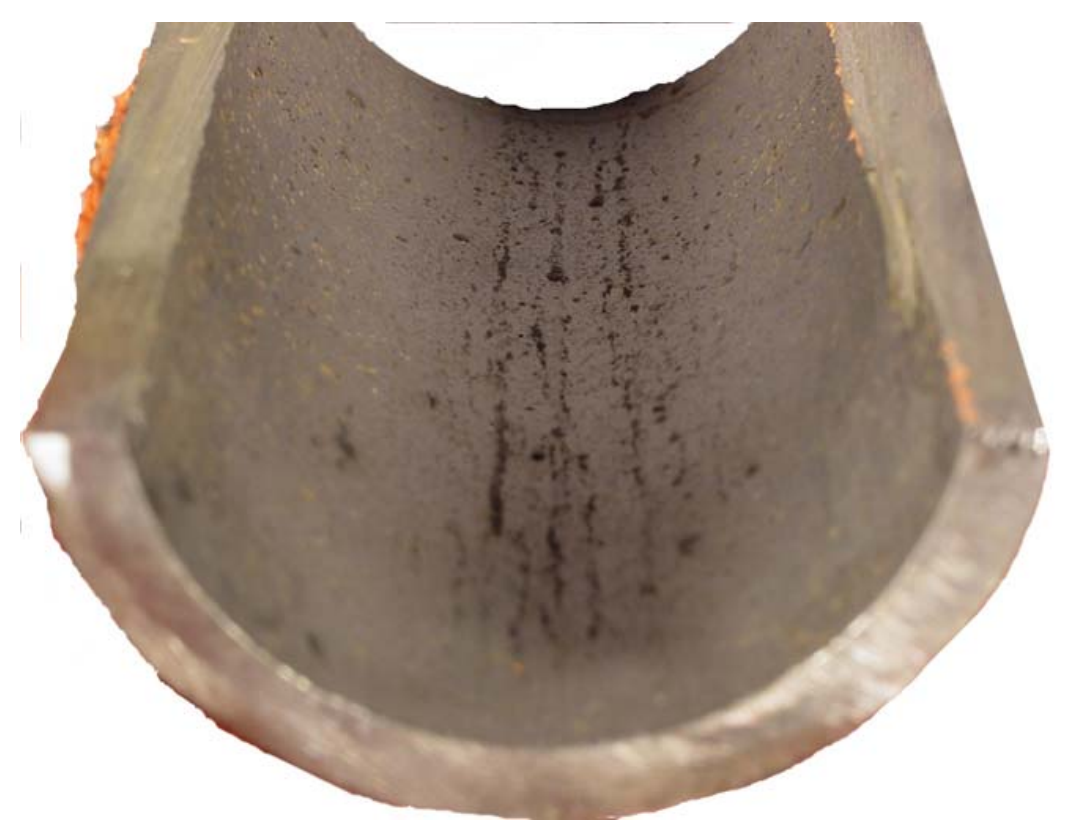

FIG 1: Photographs of the "alligator hide" appearance of the ID surface of a fossil fired boiler, vertical primary superheater tube (2-inch OD).

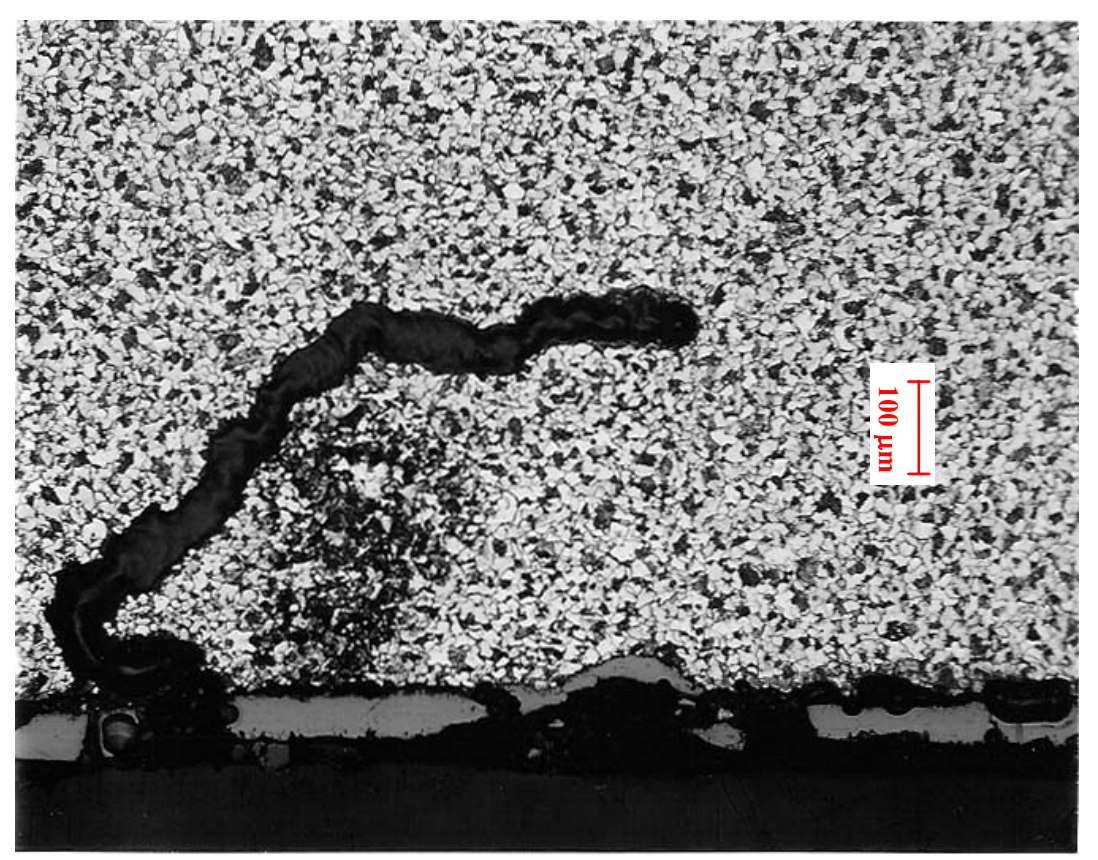

FIG 2: Micrograph of microstructural damage to the ID surface of a fossil fired boiler, vertical primary superheater tube.

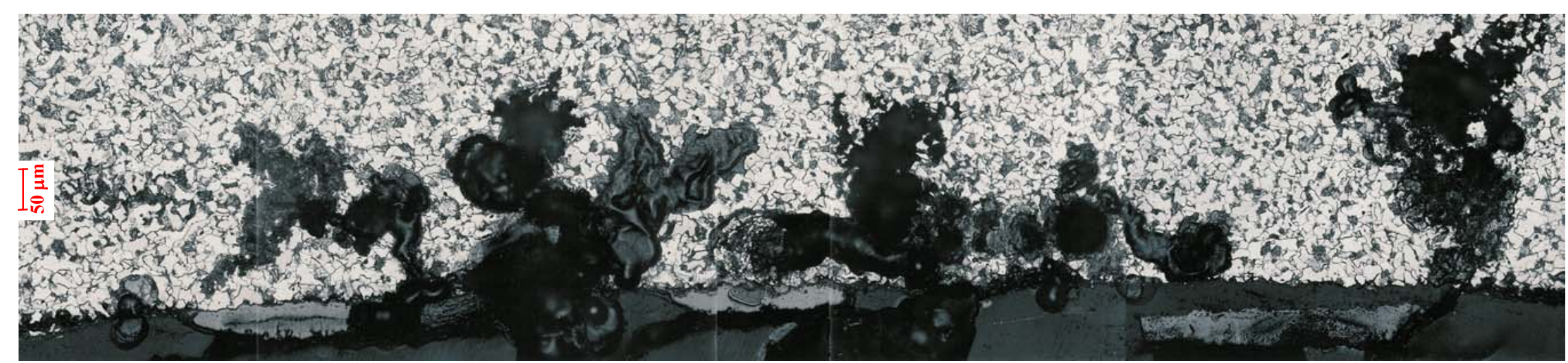

FIG 3: Micrographs of the pitting and intergranular attack at the ID surface of a fossil fired boiler, vertical primary superheater tube. 